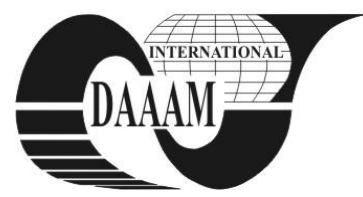

\title{
COMPARISON OF THE USING OF CRM IN ENTERPRISES IN SLOVAKIA AND HUNGARY
}

\author{
VICIKOVA, J[aroslava] \& MARKOVA, P[etra]
}

\begin{abstract}
The customer relationship management is the term well known in services and telecommunication sphere, but less known in manufacturing and industrial enterprises. The article describes utilization customer relationship management in medium and large manufacturing; industrial enterprises in conditions of Slovakia and Hungary and compares differences and similarities between two bordering countries.
\end{abstract}

Key words: customer, relationship management, enterprise, knowledge

\section{INTRODUCTION}

The Customer Relationship Management or CRM is a number of strategies and technologies which are used to build stronger relationships between enterprises and their customers. An enterprise will store information that is related to their customers, and they will spend time analysing it, so it can be used for this purpose (Jonghyeok et al., 2003). The idea of CRM is that it helps businesses use technology and human resources to gain insight into the behaviour of customers and the value of those customers. With an effective CRM strategy a business can increase revenues by (Vičíková et al., 2010):

- providing services and products that are exactly what customers want,

- offering better customer service,

- cross selling products more effectively,

- helping sales staff close deals faster,

- retaining existing customers and discovering new ones. Customer relationship management is the "philosophy" of enterprise, which helps to improve customer interactions, to build and improve relationships with customers and thus increase competitiveness (Burnett, K. 2005). Comparing situation with CRM in western states of the European Union and CRM in the Slovakia, we find out that in Slovakia CRM is obviously lagging. This paper compares utilization CRM in industrial enterprises of two post-communist, Central European countries. (Slovakia and Hungary).

\section{METHODS AND MATERIALS USED FOR RESEARCH}

The main objective of the research was to determine knowledge and use of CRM in medium and large, industrial enterprises in Slovakia and Hungary. To determine the stated objective it was necessary to use several methods and approaches, which were: managed personal interviews (with experts on the issues in enterprises), questionnaire research (in the Slovak Republic and Hungary) and statistical methods (onedimensional descriptive statistics - frequency table, pie diagrams, one-inductive statistics -statistical significance test). Also were used other methods like methods of analysis, synthesis, deduction, induction and comparison. Research was attended by 76 enterprises (60 from Slovakia and 16 from Hungary). One questionnaire always represented the situation in one enterprise. Data from the questionnaires were distributed and collected electronically. All questions were answered by managers (sales manager, marketing manager and sales and training manager, quality manager) and also head of various sections in enterprise (head of commercial department, etc.) For the purpose of research were developed 5 hypotheses:

Hypothesis H1: Enterprises with foreign capital participation are familiar with the contents of a customer relationship management better than enterprises with the participation of the Slovak and Hungarian capital.

Hypothesis H2: Enterprises with foreign capital participation use customer relationship management more frequently than enterprises with participation of the Slovak and Hungarian capital.

Hypothesis H3: It is supposed, that $50 \%$ of businesses has established a comprehensive system for managing customer relationships.

Hypothesis H4: It is supposed, that $50 \%$ of businesses undertake educational activities and training-oriented customer care.

Hypothesis H5: It is assumed, that enterprises don't take care on cultural differences of their customers.

\section{RESULTS}

Results obtained in both countries are very similar. This is mainly due to the similar situation in enterprises and also due to near position of both countries.

Responses from both countries will be compared and the differences or similarities will be described in this part of article. The main questions and also the answers of the empirical research findings and results can be interpreted as follows. The most important findings are, if the enterprises know the customer relationship management and also if they use the principles of customer relationship management in their enterprises.

The figure 1 describes knowledge of CRM, 77\% of enterprises in Slovakia and $75 \%$ of enterprises in Hungary have knowledge about CRM. It is clear that CRM is for enterprises operating in Slovakia and Hungary good known and it does not affect the type of ownership structure.

The situation is different in the use of CRM in enterprises, only $50 \%$ of enterprises in Slovakia use principles of CRM, in Hungary the percentage is even lower, only $44 \%$. CRM is used in this case more frequently by companies with foreign capital participation.

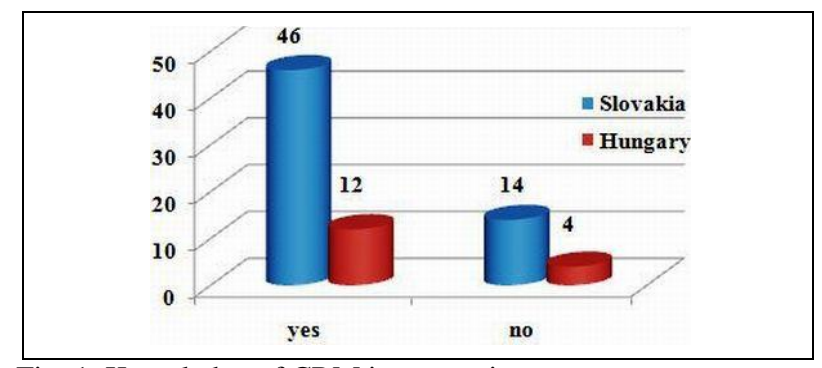

Fig. 1. Knowledge of CRM in enterprises 


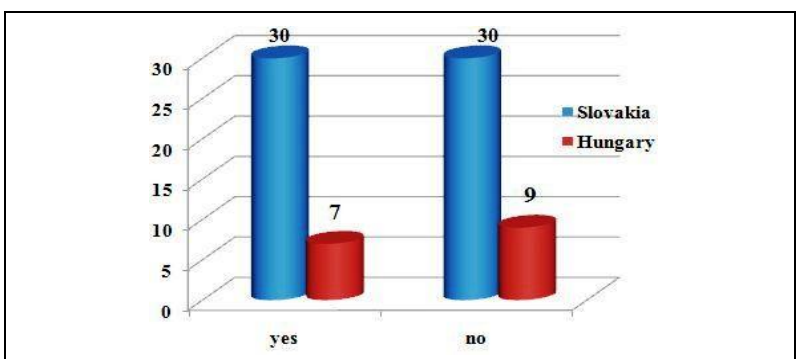

Fig. 2. Utilization of CRM in enterprises

Another question was directed to determine, whether companies have a comprehensive CRM system. Only 25\% of enterprises in Hungary and 33\% of enterprises in Slovakia have established integrated CRM system. The positive is fact that enterprises are planning to establish the system within two years. The positive is that enterprises have built software to support customer relationship management. Most enterprises use ERP systems/software (40\% share in Slovakia, 50\% in Hungary) only $20-25 \%$ is used CRM system.

The right approach, adequate and professional behavior of employees to the customer is very important for building and maintaining relationships with customers. Educational activities focused on the customer carries out more than 50\% of enterprises. Enterprises are trading also with foreign customers, so it is necessary to know the cultural differences of customers and cultures. Figure 4 represents how enterprises educate their employees in area of customer cultural differences. In Slovakia and also in Hungary enterprises don't pay enough attention to the cultural differences of their customers. Only 23\% of enterprises in Slovakia and 19\% of enterprises in Hungary realize educational activities in this field.In consideration on given facts it is possible to prove or disprove the mentioned hypothesis. The knowledge of customer relationship management doesn't depend on the ownership structure of the enterprise, hypothesis H1 is therefore not accepted, exactly opposite situation is in the case of hypothesis $\mathrm{H} 2$, so $\mathrm{H} 2$ is proved.

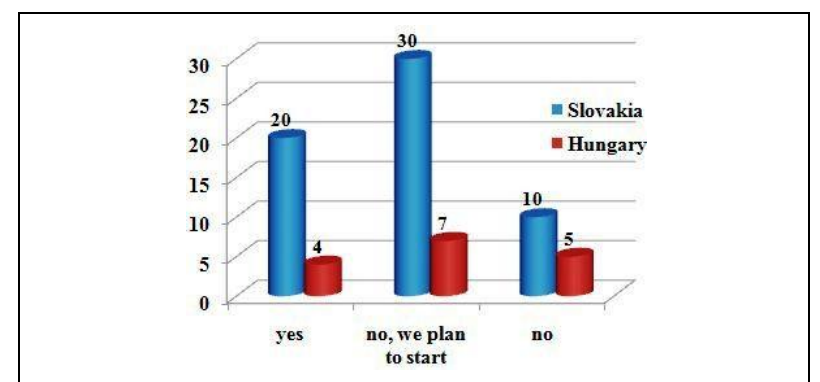

Fig. 3. Utilizing of CRM system in enterprises

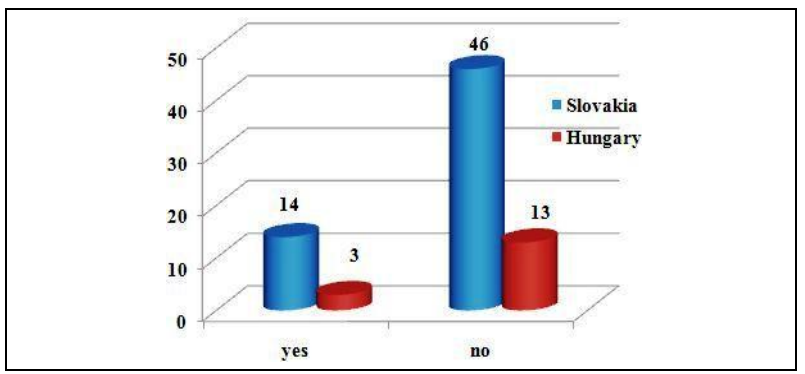

Fig. 4. Cultural differences of customers and educational activities in enterprises

Comprehensive system for managing customers uses only about $30 \%$ of responded enterprises, so the hypothesis $\mathrm{H} 3$ is disproved. Up to $54 \%$ of enterprises conducted educational activities focused on customer care, while implementation of these activities depends on the ownership structure and number of customers. The hypothesis H4 is accepted. Despite the fact that $90 \%$ of enterprises is trading with foreign customers, only $22 \%$ of enterprises educate their employees in area of customer cultural differences. The hypothesis $\mathrm{H} 5$ is accepted.

According to the present research and also according to research compiled by Mr. Lendel, we can conclude (Lendel, 2011), (Vičíková et al., 2011):

- Top management does not pay enough time and space for customer related problems,

- Enterprises are familiar with CRM, but only few of them also use CRM,

- Customer satisfaction survey in enterprises,

- Small number of enterprises use for customer relationship management CRM software systems,

- Performance targets are rarely evaluated in a quantitative way according to concrete customers,

- Level of CRM is based on industry in which the enterprise operates and also it's based on ownership structure of the enterprises,

- $\quad$ Situation with CRM utilization in industrial enterprises in Slovakia and Hungary is very similar,

- Competencies for customer relationship management are divided among several departments in enterprises.

\section{CONCLUSION}

Often, the philosophy of customer relationship management is wrongly understood only as software or project after reaching a certain destination is closed (Vičíková, 2010). It is very important for enterprises operating in Slovakia and Hungary to understand that CRM is not only fashionable thing, but the whole philosophy of the company from top management to their employees.

\section{ACKNOWLEDGEMENTS}

This paper is a part of a doctoral thesis: Vičíková, J. (2010). The proposal of the procedure for applying the principles of customer relationship management in logistics.

\section{REFERENCES}

Burnett, K. (2005). Key customers and care for them, CP Books, ISBN 80-7226-655-1, Brno

Jonghyeok, K.; Euiho,S. \& Hyunseok H.(2003). A model for evaluating the effectiveness of CRM using the Balanced Scorecard, Available from: http://www3.interscience.wiley.com/cgi-bin/home Accessed: 2011-05-29

Lendel, V. (2011). The level of customer relationship management in Slovak enterprises. Available from: http://dspace.upce.cz/bitstream/10195/35641/1/LendelV_Ur ovenVztahov_SP_FES_2009.pdf Accessed: 2011-07-25

Vičíková, J.; Czifra, J. \& Szabó, P. (2010). Application of CRM systems in logistics and their economic evaluation, No 1. Annals of DAAAM for 2010 \& Proceedings of the 21st International DAAAM Symposium "Intelligent Manufacturing \& Automation: Focus on Interdisciplinary Solutions", 20-23 ${ }^{\text {rd }}$ October 2010, Zadar, Croatia, ISSN 1726-9679. - Vol. 21, ISBN 978-3-901509-73-5, Vičíková, J. (Ed.), pp. 1147-1148, Zadar - Vienna: DAAAM International Vienna, 2010.

Vičíková, J.; Chatrnúchová, L. \& Ondrušková, O. (2011). CRM usage in industrial enterprises in the Slovak republic, Quare 2011: Interdisciplinary peer-reviewed Proceedings of the International Conference of PhD students, $25-29^{\text {th }}$ April 2011, Hradec Králové, CZK, ISBN 978-80-904877-3-4., Vičíková, J. (Ed.), pp.597-602, Magnanimitas, Hradec Králové 